\title{
Performance of a photogrammetric digital elevation model in a tropical montane forest environment
}

\author{
Wilson V. C. Wong ${ }^{*{ }^{* 2}}$, Satoshi Tsuyuki*1 ${ }^{* 1}$ Mui-How Phua*2, Keiko Ioki² ${ }^{* 2}$ and Gen Takao*3
}

\begin{abstract}
Digital photogrammetry has advanced to the point where digital elevation models (DEMs) can be derived in full automation from stereo images, offering new opportunities in various fields including forestry. However, the performance and limitations of digital photogrammetry need to be carefully investigated in forest environments where both scientific studies and forest management depend on accurate information. We evaluated the performance of a photogrammetric digital surface model (photo-DSM) derived from small-format aerial photographs over approximately 2000 ha of tropical montane forest in northern Borneo, Malaysia. The accuracy of the photo-DSM was evaluated by using a reference dataset derived from airborne laser scanning (ALS) with an approximate density of 15 pulses $/ \mathrm{m}^{2}$. The vertical accuracy over the total area (18,349,288 pixels) was represented by a mean error of $0.006 \mathrm{~m}$ and RMSE of $3.003 \mathrm{~m}$, with $61.1 \%$ of all measured heights accurate to within $\pm 1 \mathrm{~m}, 81.9 \%$ accurate to within $\pm 2 \mathrm{~m}$, and $88.7 \%$ accurate to within $\pm 3 \mathrm{~m}$. More detailed local accuracy evaluation was conducted at block level: 31 1-ha blocks and one 0.25 -ha block located over different forest types and characterized by the mean canopy height (range=8.4-41.1 m) and standard deviation (range $=2.0-9.8 \mathrm{~m}$ ) of the ALS-canopy height model (ALS-CHM). RMSE of the forest blocks ranged from 1.01 to $4.19 \mathrm{~m}$, and this variance in RMSE could be explained by $78.6 \%$ of standard deviation of the ALS-CHM. Canopy slope and dark areas also had an effect on the RMSE: in areas of higher canopy slope and in darker areas within the forest blocks, the RMSE increased by up to 8.6 and $5.8 \mathrm{~m}$, respectively. No-data areas accounted for $3.24 \%$ in the forest blocks and were also influenced by canopy slope and darker areas. RMSE of non-forest areas was $0.39 \mathrm{~m}(n=5243$ pixels). Research and development on image-matching algorithms (which achieved $86.1 \%$ successful alignment of the aerial photographs in our study), cameras, unmanned aerial vehicles, and flight parameters are ongoing; as a result, digital photogrammetry and its capacity for use in various forestry applications are also continuing to improve.
\end{abstract}

keyword: tropical montane forest, digital surface model (DSM), digital photogrammetry, small-format aerial photographs

\section{INTRODUCTION}

The forest canopy is an important subcomponent of the forest ecosystem and plays a major role in many forest

Corresponding author: Wilson V. C. Wong

(E-mail:w.wilson@ums.edu.my)

${ }^{* 1}$ Graduate School of Agricultural and Life Sciences, University of Tokyo, 1-1-1 Yayoi, Bunkyo-ku, Tokyo 113-8567, Japan

${ }^{* 2}$ Faculty of Science and Natural Resources, Universiti Malaysia Sabah, Jalan UMS, 88400 Kota Kinabalu, Sabah, Malaysia

${ }^{* 3}$ Forestry and Forest Products Research Institute, Matsunosato 1, Tsukuba, Ibaraki 305-8687, Japan processes and functions. For example, it is the interface between the forest and the atmosphere (e.g. Parker et al., 1992), an area of major photosynthetic activity (e.g. Carswell et al., 2000), a biotic habitat (e.g. Erwin, 1983; Kays and Allison, 2001), and a site of ecological interaction within the forest ecosystem (e.g. Nadkarni, 1994). The complexity of forest canopy lies not only its structure but in the various ways to conceptualize and describe it (e.g. Bongers, 2001; Parker and Brown, 2000). One definition of the canopy is the outermost representation of the canopy surface (Bongers, 2001). In the past, three-dimensional descriptions of the forest canopy were the main challenge, especially in terms of physical access (Barker and Pinard, 2001; Lowman and Wittman, 1996) and resource intensiveness of reconstructing a threedimensional representation (Bongers, 2001). The advancement of remote sensing technologies (i.e. LiDAR, InSAR [interferometric synthetic aperture radar], and photogrammetry ) has enabled fully automated 
reconstruction of the forest canopy surface over large spatial areas with high accuracy and highly detailed information, depending on the sensor type and flight parameters (e.g. acquisition height and speed). Among the three techniques available for forest canopy reconstruction, photogrammetry has several advantages, especially in terms of its low cost and the presence of reflectance information (Leberl et al., 2010).

In analytical photogrammetry, the height information is derived manually by using an analytical stereo-plotter to measure the elevation in each cell of an operational gridtypically $2.5 \mathrm{~m}$ (e.g. Fujita et al., 2003a; Okuda et al. 2004) or 5 m (e.g. Nakashizuka et al., 1995)-constructed over the image. This technique is resource intensive where study areas are typically limited to 100 ha (e.g.1600 points/ha are required for $2.5 \mathrm{~m}$ grid), and this drawback has impeded the use of photogrammetry for large-scale operations in forest areas. The most recent innovation in photogrammetry technology is digital photogrammetry, in which height elevation can be derived fully automatically. Digital photogrammetry technology is made possible by the development of imagematching algorithms, integrated GNSS/IMU navigation system, graphics processing units (GPUs), and digital photography (e.g. Leberl et al., 2010). In addition to the ability to derive height information from stereo-pair images, aerial photographs also provide a range of unique fundamental characteristics such as color, tone, and texture from the reflectance information (Morgan et al., 2010) with high geometric resolution (Kardoš, 2013) and at relatively low cost. Aerial photography also has the ability to collect the same set of data three times as efficiently in terms of person-hours than the conventional field approach (Brown et al., 2005). This leads to more precise analysis of forest structure (Bongers, 2001) and aerial photography is thus used for various forestry applications such as key data sources for forest inventory and land cover classification of accuracy assessment (Imai et al., 2009; Phua et al., 2008; White et al., 2013), wildlife surveys (Vermeulen et al., 2013), and stand parameter estimation (Awaya et al., 2000), including manual stand delineation and visual interpretation of species (e.g. Garzon-Lopez et al., 2013; Valérie and Marie-Pierre, 2006) or semi-automatically when using multi-spectral imagery (e.g. Hirata et al., 2014). It is currently not possible to conduct these types of analyses by InSAR or airborne laser scanning (ALS).

The three-dimensional information derived from aerial photographs offers huge potential, especially when a highquality digital terrain model derived from ALS is available. Numerous studies have taken advantage of digital photogrammetry in forestry applications, especially in the estimation of forest variables such as diameter at breast height, tree height, basal area, and volume per hectare using photogrammetric height metrics in plot-based (e.g. Bohlin et al., 2012; Järnstedt et al., 2012; Gobakken et al., 2015; Nurminen et al., 2013; Straub et al., 2013; Vastaranta et al., 2013; Wong et al., 2015), and its use is reported to rank second after ALS and better than InSAR and radargrammetry for timber volume estimation (Rahlf et al., 2014). However, the success of using height metrics in plot-based for those purposes does not represent the performance and accuracy of photogrammetric DEMs at pixel resolution level, where this type of information would be important for other detailed studies such as monitoring forest dynamics or forest gap study (e.g. Bongers, 2001; Fujita et al., 2003b). Although several studies have attempted to evaluate photogrammetric DEMs in different environments such as in mountain environments (e.g. Müller et al., 2014), our understanding of the performance of photogrammetric DEMs in complex forest environments, especially in tropical rainforests, remains poor (Miller et al., 2000; White et al., 2013) and more studies are needed to contribute to the robustness of digital photogrammetry technology for forestry applications. Slope (e.g. Müller et al., 2014) and shade (Baltsavias et al., 2008) are reported to affect the performance of digital photogrammetry, and those characteristics often exist in forest environments, especially in the heterogeneous forest structures of primary rainforest.

In this study, we investigated the performance of a photogrammetric DSM (photo-DSM) in the forest environment of a tropical montane forest by using canopy height metrics (i.e. mean and standard deviation [SD] of canopy height of the ALS-derived canopy height model [ALSCHM]), by using canopy slope and dark areas and by evaluating the relationship between no-data areas of the photo-DSM and both slope and dark-area class. We also discuss the advantages, limitations, and issues of digital photogrammetry in forestry applications.

\section{MATERIALS}

Study area

The study area is located in the Ulu Padas forest area (approx. $4^{\circ} 26^{\prime} \mathrm{N}, 115^{\circ} 45^{\prime} \mathrm{E}$; Fig. 1) of northern Borneo, Malaysia, inside the Heart of Borneo initiative area that, together with the Pulong Tau National park in Sarawak and the Kayan Mentarang National Park in Kalimantan, Indonesia, forms part of an important mountain eco-regional representation of Borneo. The Ulu Padas forest area covers approximately 155,000 ha in the southwestern tip of Sabah bordering North Kalimantan and Sarawak. The area is covered by rugged terrain ranging in altitude from about 1000 to $1900 \mathrm{~m}$. The vegetation of this region consists of several types (i.e. dominant montane oak/chestnut forest with Agathis spp., hill dipterocarp forest, stunted montane mossy forest, and highlevel swamp forest; SBCP, 1998). Land use consists of both small- and large-scale logging activities by timber companies and local people as well as small-scale farming activities by the local people with some portion remaining as old growth forest with the canopy height reaching up to $60 \mathrm{~m}$. The area covered by the current study is Site 1 (approx. 2000 ha) of the LiDAR and aerial photograph data acquisition flight mission conducted in October 2012. In Site 1, the elevation ranges from 961 to $1895 \mathrm{~m}$, with average slope of $18.6^{\circ}$, and is generally covered by vegetation to a mean canopy height of $22.5 \mathrm{~m}$ with SD of $9.0 \mathrm{~m}$ (information is derived from ALS data).

Aerial photograph data

The aerial photographs in the October 2012 flight 


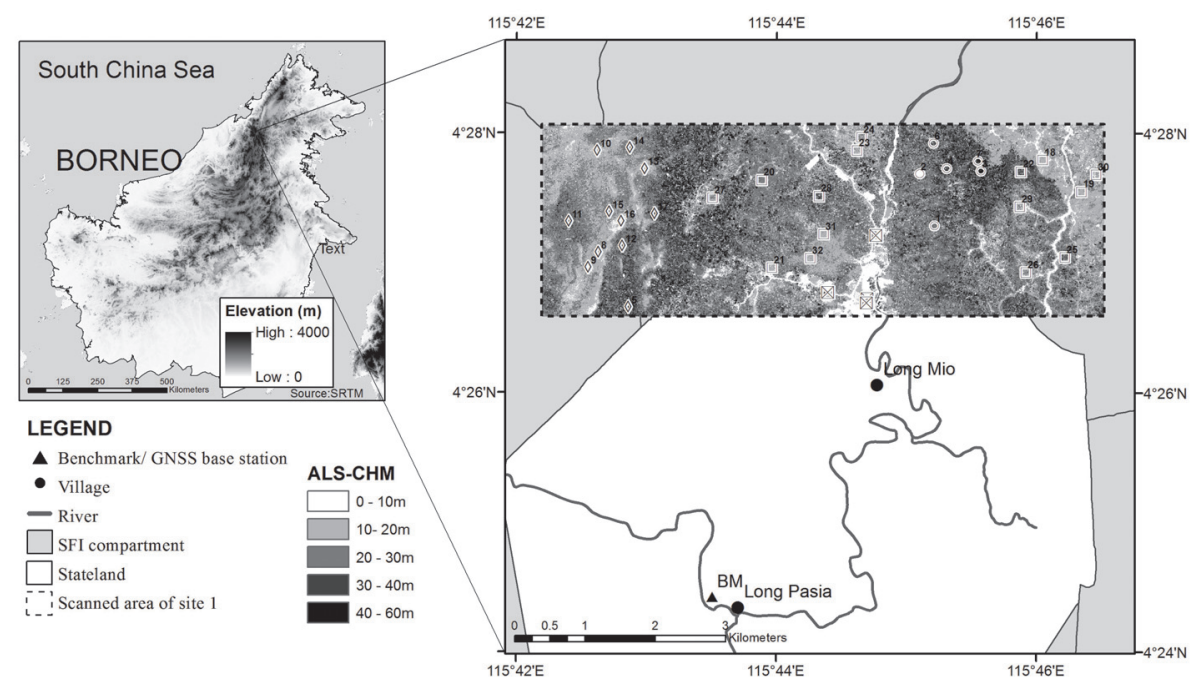

Fig. 1 Location of the study area. Site 1 (large dashed rectangle) represents the site of this study (source of elevation map: Shuttle Radar Topography Mission). Site 1 is enclosed with ALS-CHM and distribution of the forest blocks of upper montane forest (lozenge), lower montane forest (circle), and secondary forest (square), and non-forest blocks (square with cross).

mission were acquired with a small-format digital single-lens reflex camera (Canon EOS-1D Mark III) fitted with a lens with focal length of $28 \mathrm{~mm}$ and cross-track field-of-view of $52.9^{\circ}$ and along-track field-of-view of $36.6^{\circ}$. The camera was attached to a platform on a Bell 206B3 Jet Ranger helicopter, and the flight mission was conducted over 4 days at an altitude of approximately $400 \mathrm{~m}$ above ground level. However, due to the ruggedness of the terrain and also to the strong wind on the data acquisition days, the pilot had difficulty in maintaining the pre-planned flying altitude of 400 $\mathrm{m}$ above ground level during the entire flight mission. The flying altitude was calculated to have ranged from as low as $73 \mathrm{~m}$ to as high as $791 \mathrm{~m}$ with an average of $390 \mathrm{~m}$. Flying at an average speed of $100 \mathrm{~km} / \mathrm{h}$ and with an exposure interval of 3.5 s resulted in $55-70 \%$ of forward overlap and about $45 \%$ of side overlap. The camera was set with exposure time of $1 /$ $2500 \mathrm{~s}$, ISO-speed of 1250 , and aperture range from $\mathrm{f} / 1.8$ to $\mathrm{f} /$ 10. A total of 2400 aerial photographs for Site 1 were delivered in 24-bit sRGB in large-size format of JPEG (3888× 2592 pixels) with average GSD (ground sampling distance) of approximately $10 \mathrm{~cm}$, together with GNSS/IMU data information.

\section{ALS data}

The LiDAR data were acquired simultaneously with the aerial photographs. The LiDAR system (Riegl LMS-Q560; Riegl LMS GmbH, Horn, Austria) was operated with a $45^{\circ}$ of field of view and $240 \mathrm{kHz}$ pulse repetition rate with beam divergence of less than $0.5 \mathrm{mrad}$. The side overlap was within $30-50 \%$. The processed data were delivered in the coordinate system of the WGS84 UTM Zone 50N / WGS84 ellipsoid in the LAS 1.2 format (for processing information, see Ioki et al., 2014), and the point cloud, comprising 832 million points with an approximate density of $14.9 \mathrm{pulses} / \mathrm{m}^{2}$, was classified into ground and non-ground class using TerraScan software (Soininen, 2010). The vertical accuracy
(RMSE) of the points in the ALS point cloud was estimated to be within $25 \mathrm{~cm}$.

ALS is the best available reference dataset for forest ecosystem evaluation due to its non-clustering effect (Müller et al., 2014) unlike when using ground reference data from DGPS (differential global positioning system) and surveying instrument of total station (e.g. Tonkin et al., 2014). ALS is very accurate to within tens of centimeters; $15 \mathrm{~cm}$ for flat forest areas and increasing with terrain slope to a value about $40 \mathrm{~cm}$ at a slope of $40 \%$ for DTM (Hyyppa et al., 2000).

\section{METHODS}

Image-matching process

The aerial photographs were processed with a digital photogrammetry software package employing the structure from motion (SfM) technique (Agisoft Photoscan Pro 1.0.3; Agisoft, St. Petersburg, Russia). SfM technique aims to simultaneously reconstruct three-dimensional scene structure, camera positions and orientations from a set of overlapping photographs (Snavely et al., 2008). The workflow required to produce a dense photogrammetric point cloud consists of two stages (Agisoft, 2014). The first stage is camera alignment, in which image matching is executed to create a sparse point cloud model by searching for common points on the photographs as well as the position of each photograph, and using this information to refine camera calibration parameters. In this process, we used 2400 aerial photographs and the GNSS/IMU data to generate a sparse point cloud of 3,172,874 points covering an area of about 2300 ha. The GNSS dataset collected with 1 hertz was postprocessed using differential GNSS technique (Waypoint GrafNet version 8.4; NovAtel Inc., Alberta, Canada). Muller et al. (2014) performed co-registration assessment and demonstrated that offset is $<25 \mathrm{~cm}$, which is smaller than the 
GSD. Of the 2400 photographs, 2067 (86.1\%) were successfully aligned. The reported average camera location errors in the $x$, $y$, and $z$ directions were $1.82,0.69$, and $0.55 \mathrm{~m}$, respectively, and the total error was $2.03 \mathrm{~m}$. The second stage is building a dense point cloud, where the Photoscan software calculates depth information for each photographs and, based on the estimated camera positions, combines all of the point cloud into a single dense point cloud. In our study, the entire area needed to be divided into two blocks (each approx. 1000 ha) because of the limits of the workstation's processing capability. A dense point cloud with a total of 935 million points was generated, and then converted to LAS format for further processing. The total processing time was approximately 13 hours by using a workstation with the following specifications: Intel Core i5-4670 CPU at $3.40 \mathrm{GHz}$, 16.0 GB installed memory (RAM), 64-bit OS, and NVIDIA Quadro K2000 GPU.

The whole process was performed in full automation, with us setting only the initial software parameters. For the camera alignment stage, we used the following parameters: high image matching, point limit of 40,000, and with ground control (i.e. GNSS/IMU data), together with optimization of fit aspect, skew transformation coefficient, focal length, principal point coordinates $(c x, c y)$, radial distortion coefficient $(k 1, k 2$, $k 3$ ), and tangential distortion coefficient $(p 1, p 2)$. For the point cloud densification stage, we used the following parameters: quality of 'high' with advanced option of 'mild'. The settings for these built-in parameters were decided based on evaluation analysis employing forward sequential selection (e.g. Järnstedt et al. 2012) to determine the best settings in a 100 ha test area. This is important; otherwise even a robust matching method would produce an unsatisfactory threedimensional reconstruction (Remondino et al., 2014).
DSM, digital terrain model, and CHM generation

A photogrammetric digital surface model (photo-DSM) of 1-m pixel resolution was derived by using LAStool in the ArcGIS 10.1 software package (ESRI Inc., Redlands, CA, USA). The maximum value in the point cloud in each $1 \mathrm{~m} \times 1$ $\mathrm{m}$ pixel grid was used to compute the photo-DSM height (Fig. 2a). The same procedure was applied to derive the digital surface model of the reference dataset (ALS-DSM). ALS points of ground class were used to generate the digital terrain model (ALS-DTM) by using triangulation with natural neighbor interpolation. Then, canopy height models (ALS-CHM and photo-CHM) were derived by subtracting the ALS-DTM from the respective ALS-DSM and photo-DSM. A spatial resolution of $1 \mathrm{~m}$ was used because it has been tested and shown to produce high-performance results in the same study area (Wong et al., 2014) and also because it has been used in several other studies (e.g. Bühler et al., 2012; Hese and Lehmann, 2000; Hobi and Ginzler, 2012). We manually masked out problematic areas $(264.29$ ha) where the aerial photographs did not successfully align during image matching.

\section{Canopy height characterization}

Forest canopies are extremely complex, and forest canopy descriptions are difficult to conceptualize (e.g. Parker and Brown, 2000). In this study, we used mean and SD of canopy height (e.g. Hawbaker et al., 2009; Pascual et al., 2010) from the ALS-CHM to characterize the forest canopy structure. Vegetation zones are also complex: inconsistencies in designating zones can be found even in the same mountain (Kitayama, 1992), notwithstanding the Massenerhebung effect (Grubb, 1971) in which altitudinal limits can vary with the type of mountain in similar regions, and patchiness can be
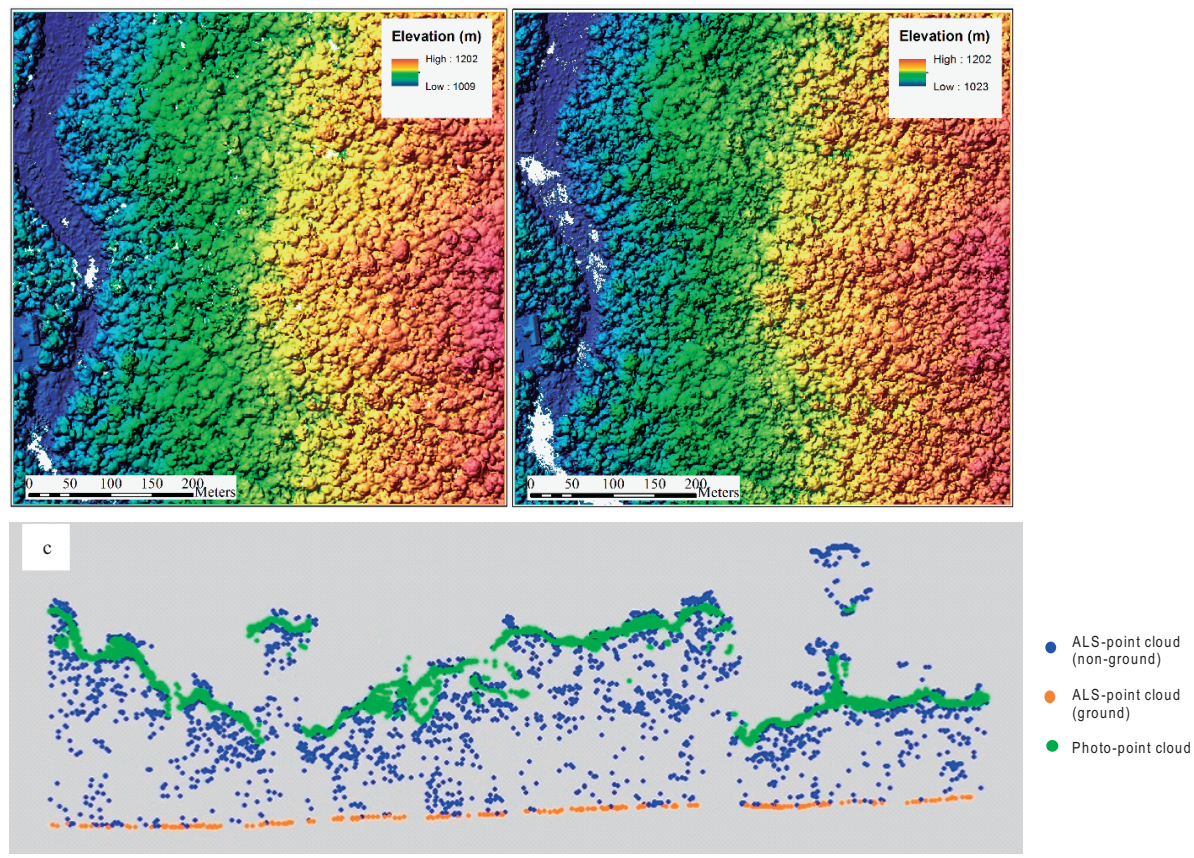

Fig. 2 (a) Photogrammetric digital surface model with shaded relief (1-m pixel resolution); (b) ALS digital surface model with shaded relief (1-m pixel resolution); (c) Cross sectional profile $(1 \mathrm{~m} \times 100 \mathrm{~m})$ illustrating the photogrammetric and ALS point cloud. 
found in transitional zones (e.g. Pearce, 2006). Pearce (2006) found patches of lower montane forest occurring at altitudes of 950 to $1750 \mathrm{~m}$, while patches of upper montane forest could occur at low altitudes of $1300 \mathrm{~m}$ up to summits in similar ecoregional areas. The description of forest type or vegetation zone can be attributed to species composition (e.g. Pearce, 2006) as well as to soil type (Kitayama, 1992). Therefore, due to the limited information of species composition and soil type in categorizing forest type in this area, we arbitrarily defined $1600 \mathrm{~m}$ as the altitudinal line separating upper montane primary forest (PU) and lower montane primary forest (PL), and we designated regenerating logged areas and areas of abandoned shifting cultivation as secondary forest (SF) (Fig. 1). By visual observation of the ALS-CHM, we created 32 forest blocks (Fig. 1) of 1 ha each (except for one block which was 0.25 ha) each representing a different mean and SD for ALS-derived canopy height. Upper montane forest in the study site typically consisted of vegetation with a lower mean canopy height (average $=21.2 \mathrm{~m}$ ) and lower SD (average $=4.1 \mathrm{~m})$ in the ALS-CHM, whereas lower montane forest had a higher mean canopy height (average $=32.3 \mathrm{~m}$ ) and higher $\mathrm{SD}$ (average $=6.9$ $\mathrm{m}$ ) in the ALS-CHM (Fig. 3). We identified secondary forests caused by shifting cultivation and logging activities based on fieldwork observations in combination with visual interpretation of the geometrically corrected aerial photo (ortho-photo) and the ALS-CHM. The mean canopy height in each block ranged from 8.4 to $41.1 \mathrm{~m}$ and SD ranged from 2.0 to $9.8 \mathrm{~m}$. We also generated evaluation blocks $(n=4)$ from the observation of the ALS-CHM and/or orthophoto for nonforest areas consisting of roads and bare areas of paddy field (square with cross in Fig. 1), so that comparable evaluation with other studies in non-forest areas could be performed. These non-forested evaluation blocks were smaller and varied in size ( 0.05 to 0.54 ha) because the study area is dominated by vegetation cover.

\section{Canopy slope and dark areas}

We derived canopy slope for each pixel from the ALSDSM, ALS-CHM, and photo-DSM, and classified them in $10^{\circ}$ bins (Fig. 4 and Fig. 5b). Because the slope was derived from the canopy top surface instead of using a digital terrain model, we termed it 'canopy slope'. Canopy slope derived from an ALS-CHM (also referred as a normalized DSM [nDSM]) can be influenced by the steepness of the terrain and the crown shape (Khosravipour et al., 2015); therefore, it is recommended to use an ALS-DSM or photo-DSM to derive canopy slope. We generated a RGB color orthophoto mosaic from the aerial photographs with a spatial resolution of $25 \mathrm{~cm}$ using Agisoft Photoscan Pro 1.0.3. (Fig. 5a). We then performed PCA transformation of the orthophoto using ArcGIS 10.1., and manually determined the threshold digital number (DN) of PCA component 1 (hereafter PCA1) to differentiate bright areas (PCA1 DN> 205) and dark areas (PCA1 DN $\leq 205)$. Dark areas were categorized into 7 classes (Fig. 5c). The cumulative contribution of PCA1 was $94.19 \%$ and the coefficient for R, G and B were $0.673,0.596$ and 0.439 , respectively.

\section{Height accuracy assessment}

Height accuracy was assessed by calculating the difference in $z$-value $\left(\Delta h_{i}\right)$ between the photo-DSM and corresponding reference data of the ALS-DSM, and then calculating the following statistics at global (overall) and local (block) level:

$$
\begin{aligned}
& \text { Absolute Mean Error }(A M E)=\frac{1}{n} \sum_{i=1}^{n}\left|\Delta h_{i}\right| \\
& \text { Mean Error }(M E)=\frac{1}{n} \sum_{i=1}^{n} \Delta h_{i} \\
& \text { Root Mean Square Error }(R M S E)=\sqrt{\frac{1}{n} \sum_{i=1}^{n} \Delta h_{i}^{2}} \\
& \text { Relative Root Mean Square Error }(R M S E \%)=100 \times \frac{R M S E}{\bar{y}} \\
& \text { Standard Deviation } \left.(S D)=\sqrt{\frac{1}{(n-1)} \sum_{i=1}^{n}\left(\Delta h_{i}-M E\right)^{2}}\right)
\end{aligned}
$$

where $n$ is the number of samples; and $\bar{y}$ is the mean of canopy height in the ALS-CHM.

We further analyzed the relationship between RMSE values and both canopy slope class derived from the ALSDSM (and also photo-DSM) and dark-area class (PCA1 DN value) in the region of the 32 blocks by using formulae similar to those described above.
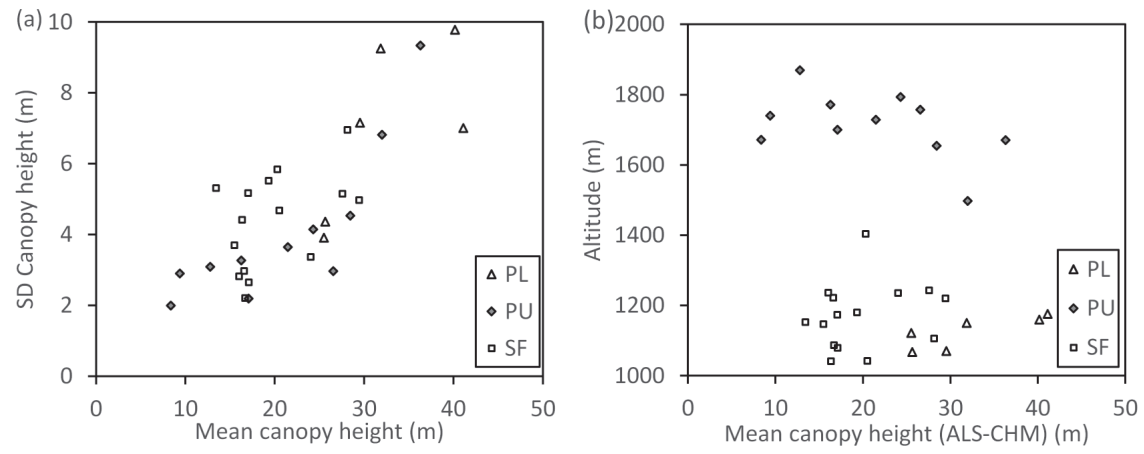

Fig. 3 (a) Forest canopy characterization using SD of canopy height against mean canopy height (ALS-CHM). (b) Altitudinal location of the blocks based on mean ALS-CHM and forest type category. PU, upper montane primary forest; PL, lower montane primary forest; SF, secondary forest. 


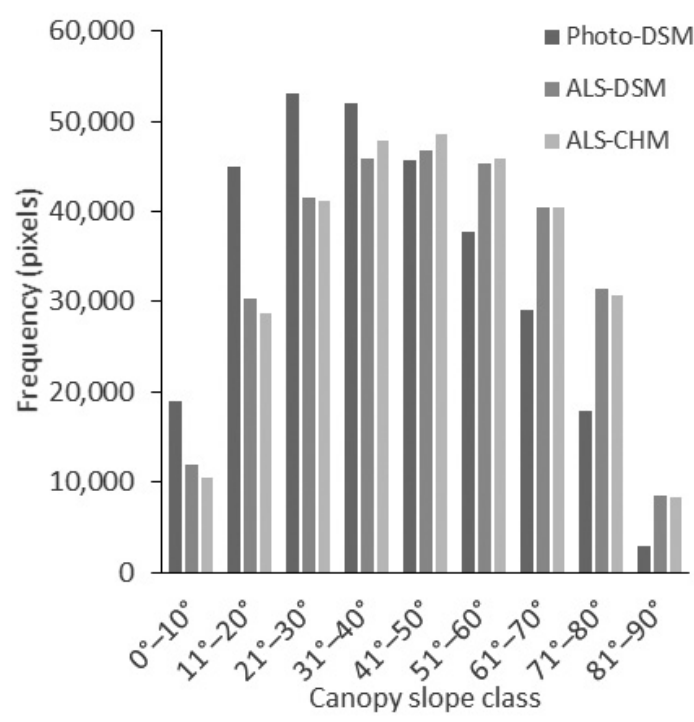

Fig. 4 Frequency of canopy slope derived from photo-DSM, ALS-DSM, and ALS-CHM.

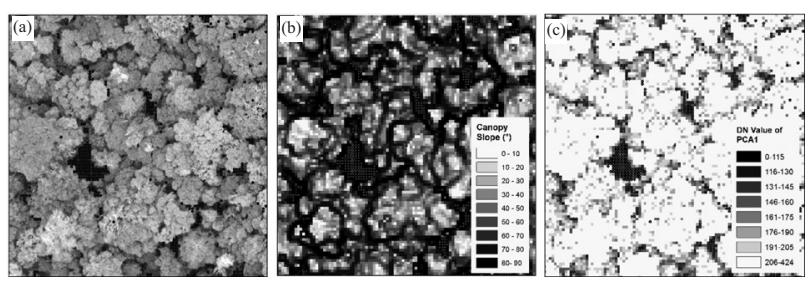

Fig. 5 (a) RGB color orthophoto of Block 4, (b) canopy slope derived from the ALS-DSM, and (c) the same area categorized by brightness class (PCA1 DN value) derived from the orthophoto. Dotted green areas represent the no-data area of the photo-DSM.

No-data areas

We examined the no-data areas in each of the 32 blocks. A no-data area is where no photogrammetric point cloud occur in a $1 \mathrm{~m} \times 1 \mathrm{~m}$ pixel of the photo-DSM. We analyzed the
Table 1 Accuracy evaluation statistics for the photo-DSM

\begin{tabular}{lcll}
\hline & Global & $\begin{array}{l}\text { Forest } \\
\text { blocks }\end{array}$ & $\begin{array}{l}\text { Non-forest } \\
\text { blocks }\end{array}$ \\
\hline Mean Error & $0.0058 \mathrm{~m}$ & $-0.0891 \mathrm{~m}$ & $-0.3152 \mathrm{~m}$ \\
RMSE & $3.0032 \mathrm{~m}$ & $2.5473 \mathrm{~m}$ & $0.3928 \mathrm{~m}$ \\
AME & $1.5160 \mathrm{~m}$ & $1.3291 \mathrm{~m}$ & $0.3207 \mathrm{~m}$ \\
Number of pixels & & & \\
$(1 \mathrm{~m}$ resolution) & $18,349,288$ & 302,184 & 5243 \\
$\Delta h_{i}$ & & & \\
$\pm 1 \mathrm{~m}$ & $61.09 \%$ & $63.19 \%$ & $98.89 \%$ \\
$\pm 2 \mathrm{~m}$ & $81.93 \%$ & $84.44 \%$ & $99.71 \%$ \\
$\pm 3 \mathrm{~m}$ & $88.73 \%$ & $90.77 \%$ & $99.85 \%$ \\
$<-3 \mathrm{~m}$ & $4.56 \%$ & $3.97 \%$ & $0.15 \%$ \\
$>3 \mathrm{~m}$ & $6.71 \%$ & $5.26 \%$ & $0 \%$ \\
\hline
\end{tabular}

RMSE, root mean square error; AME, absolute mean error; $\Delta h_{i}$, difference in $z$-value between the photo-DSM and corresponding reference data of the ALS-DSM

relationship between the no-data areas and both the canopy slope class derived from the ALS-DSM and the dark-area class (PCA1 DN value) derived from the orthophoto.

\section{RESULTS}

Overall performance of photogrammetric DSM in forest and non-forest areas

The global performance of the photo-DSM over the whole study site revealed that $61.1 \%$ of the height values fell within $\pm 1 \mathrm{~m}$ of the corresponding reference data of the ALSDSM, $81.9 \%$ fell within $\pm 2 \mathrm{~m}$, and $88.7 \%$ within $\pm 3 \mathrm{~m}$ (Table 1 ). Overestimation errors of greater than $+3.0 \mathrm{~m}$ were at $6.7 \%$, whereas underestimation errors less than $-3.0 \mathrm{~m}$ were at $4.6 \%$. The mean error, RMSE, and AME was $0.0058 \mathrm{~m}, 3.003 \mathrm{~m}$, and $1.516 \mathrm{~m}$, respectively. Evaluation of local accuracy in the forest blocks revealed the mean error, RMSE, and AME to be $-0.089 \mathrm{~m}, 2.547 \mathrm{~m}$, and $1.329 \mathrm{~m}$, respectively. The overall

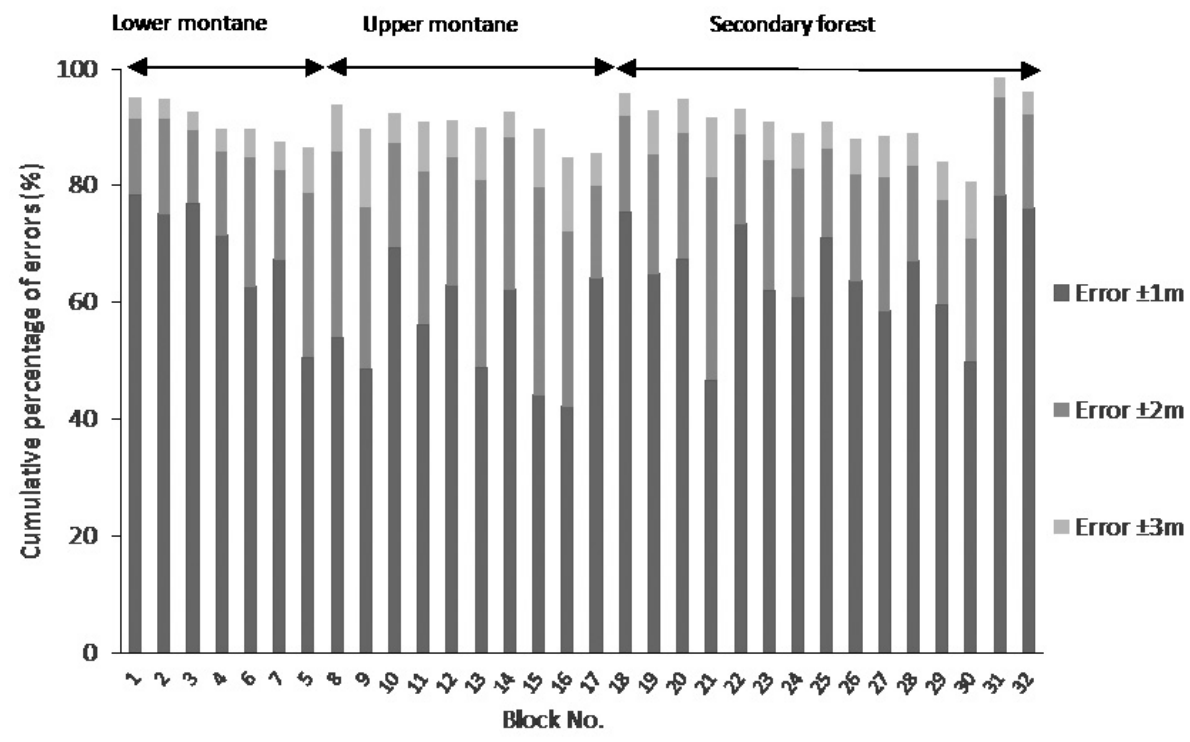

Fig. 6 Errors within $\pm 1 \mathrm{~m}, \pm 2 \mathrm{~m}$, and $\pm 3 \mathrm{~m}$ at block level over different forest categories. Error $\pm 1 \mathrm{~m}$, errors within -1 to $1 \mathrm{~m}$; error $\pm 2 \mathrm{~m}$, errors within -2 to $2 \mathrm{~m}$ excluding error $\pm 1 \mathrm{~m}$; error $\pm 3 \mathrm{~m}$, errors within -3 to $3 \mathrm{~m}$ excluding error $\pm 2 \mathrm{~m}$. 
RMSE in the four non-forest blocks (i.e. bare land of roads and paddy fields) was found to be $0.393 \mathrm{~m}$ with mean error of $-0.315 \mathrm{~m}$.

Performance of photogrammetric DSM in forest blocks

The average percentage of error within $\pm 1 \mathrm{~m}, \pm 2 \mathrm{~m}$, and $\pm 3 \mathrm{~m}$ was $72.0 \%, 87.6 \%$, and $91.6 \%$ respectively for lower montane forest blocks; $54.9 \%, 81.5 \%$, and $89.8 \%$ respectively for upper montane forest blocks; and $65.0 \%, 84.8 \%$, and $91.0 \%$ respectively for secondary forest blocks (Fig. 6). Overestimation greater than $3 \mathrm{~m}$ was observed to be highest in lower montane forest blocks (average $=5.9 \%$; $\max =10.1 \%$ ), whereas underestimation lower than $-3 \mathrm{~m}$ was observed to be highest in upper montane forest blocks (average $=5.2 \%$; $\max =12.9 \%$ ). RMSE, AME, ME, and SD of the photo-DSM accuracy in each of the blocks ranged from 1.01 to $4.19 \mathrm{~m}, 0.71$ to $2.09 \mathrm{~m},-1.11$ to $1.01 \mathrm{~m}$, and 0.97 to $4.08 \mathrm{~m}$, respectively.

\section{Effect of ALS-CHM metrics on RMSE}

Our results revealed a linear relationship between RMSE for a block and both the ALS-CHM mean $\left(R^{2}=0.295\right)$ and the ALS-CHM SD $\left(R^{2}=0.786\right)$ for the corresponding block (Fig. 7a \& 7b). Higher RMSE of $>3 \mathrm{~m}$ was typically observed in blocks with a complex canopy height structure, where ALS-CHM mean and SD of canopy height were greater than
30 and $5 \mathrm{~m}$, respectively.

\section{Effect of canopy slope and dark areas on RMSE}

We tested the relationship between RMSE and the canopy slope classes derived from both the ALS-DSM and the photo-DSM. The result demonstrated that the RMSE exhibited an exponential relationship with slope class, ranging from $1.14 \mathrm{~m}$ on the gentlest canopy slopes $\left(0-10^{\circ}\right)$ up to $8.63 \mathrm{~m}$ on the steepest canopy slopes $\left(81^{\circ}-90^{\circ}\right)$. The result on RMSE when using canopy slope derived from the photoDSM was very similar (Fig. 8a). A significant positive relationship between RMSE and canopy slope was observed (Table 2), with the strongest correlation occurring at the $>$ $70^{\circ}$ threshold $(r=0.924, P<0.001)$.

The correlation between dark-area pixels and RMSE for those pixels showed that RMSE was highest for the darkest class (RMSE $=5.8 \mathrm{~m}$ ) and decreased linearly with the brightness class category (RMSE $=2 \mathrm{~m}$ for the brightest class) (Fig. 8b).

\section{Underestimation and overestimation}

Overestimation and underestimation in the photo-DSM were observed to be influenced by the ALS-CHM metrics. Underestimation in the photo-DSM tended to occur in the upper montane forest (where mean and SD of the ALS-CHM
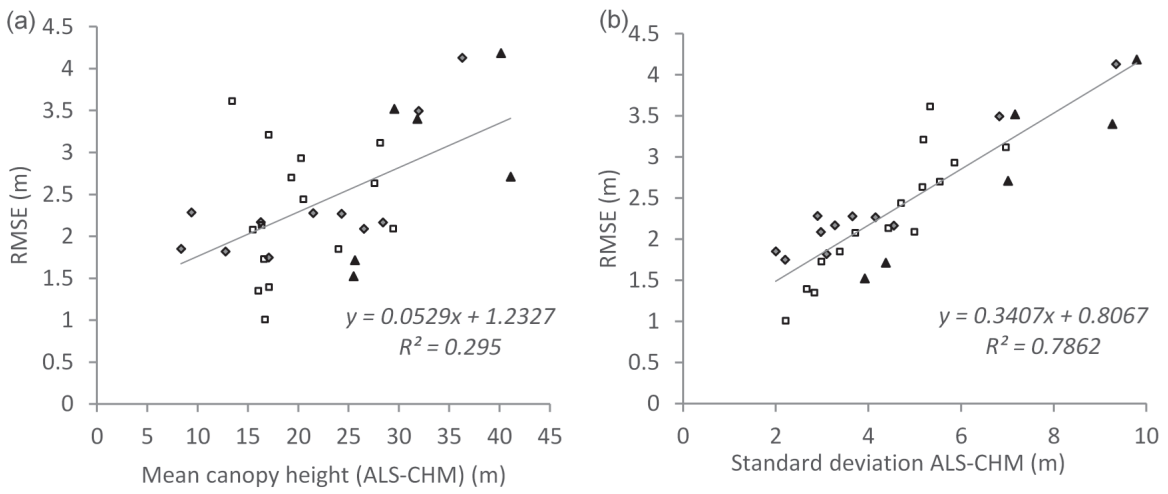

Fig. 7 (a) RMSE vs. mean of ALS-derived canopy height (m); (b) RMSE vs. SD of ALSderived canopy height (m); (c) RMSE\% vs. mean of ALS-derived canopy height; (d) RMSE\% vs. SD of ALS-derived canopy height.
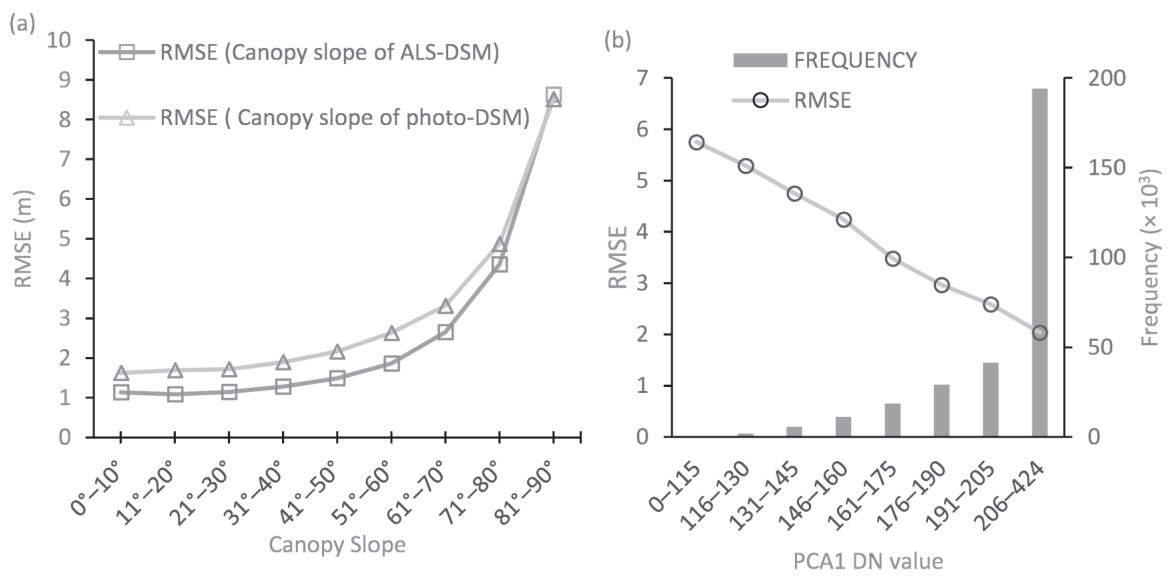

Fig. 8 Relationship between RMSE and (a) canopy slope class and (b) brightness class (PCA1 DN values). 
Table 2 Pearson correlation between RMSE and canopy slope class at different canopy slope thresholds.

\begin{tabular}{lll}
\hline Canopy slope & \multicolumn{2}{l}{ Pearson correlation coefficient } \\
\cline { 2 - 3 } threshold & ALS-DSM & Photo-DSM \\
\hline$>10^{\circ}$ & $0.6596^{* *}$ & $0.4694^{*}$ \\
$>20^{\circ}$ & $0.7101^{* *}$ & $0.5772^{* *}$ \\
$>30^{\circ}$ & $0.7750^{* *}$ & $0.6419^{* *}$ \\
$>40^{\circ}$ & $0.8338^{* *}$ & $0.7137^{* *}$ \\
$>50^{\circ}$ & $0.8713^{* *}$ & $0.7690^{* *}$ \\
$>60^{\circ}$ & $0.9028^{* *}$ & $0.7875^{* *}$ \\
$>70^{\circ}$ & $0.9244^{* *}$ & $0.7862^{* *}$ \\
$>80^{\circ}$ & $0.8948^{* *}$ & $0.7240^{* *}$ \\
$n$ & 32 & \\
\hline
\end{tabular}

${ }^{*} P$-value $<0.01 ;{ }^{* *} P$-value $<0.001$.

were lower), whereas overestimation tended to occur in the lower montane forest (where mean and SD of the ALS-CHM were higher) (Fig. 9). Overestimation was observed to occur with higher prevalence in lower montane forest as shown in the scatter plot and cross-sectional profile of a representative lower montane block (Fig. 10c). This was largely contributed to by the limitation of the photo-DSM in identifying forest gaps. Underestimation was observed with higher prevalence in upper montane forest (Fig. 10a), where trees could be missed by the photo-DSM.

Further detailed analysis of the relationship between canopy slope and mean error in each block demonstrated that underestimation of $<-0.5 \mathrm{~m}$ tended to occur in blocks with a higher proportion of gentler canopy slopes, whereas overestimation of $>0.5 \mathrm{~m}$ tended to occur in blocks with a higher proportion of steeper canopy slopes (Fig. 11a). Averages of the mean errors were underestimated in gentle canopy slopes as compared to steeper canopy slopes (Fig. 11b). Standard deviation and range of mean error were higher in steeper canopy slopes, particularly those above $60^{\circ}$.

No-data areas

No-data pixels accounted for $3.24 \%(n=10,136)$ of the total area of the 32 blocks. At a block level, the percentage of nodata pixels ranged from $0.01 \%$ to $9.18 \%$, except for one block (i.e. block no. 17) in which the percentage was exceptionally high (20.91\%). We found a moderately strong linear relationship between the percentage of no-data pixels (\%) and both ALS-CHM mean $\left(R^{2}=0.197\right)$ and ALS-CHM SD $\left(R^{2}=\right.$
0.359) (Fig. 12).

Effect of canopy slope and brightness values on no-data pixels

The proportion of no-data pixels was plotted against ALS-DSM canopy slope class (Fig. 13a) and against brightness class of the PCA1 component derived from the orthophoto (Fig. 13b). The steepest canopy slope class and the darkest class $(0-115 \mathrm{DN})$ had the largest proportion of no data at $20.17 \%$ and $23.58 \%$, respectively. No-data pixels in the photo-DSM constituted $40.79 \%$ of the no-data pixels in the ALS-DSM. Fig. 14 shows the cross tabulation of no-data pixels $(n=10,136)$ between canopy slope and dark area. Of the no-data pixels in the gentlest and steepest canopy slope classes, $26.67 \%$ and $82.70 \%$ were of the dark class category( $\leq$ $205 \mathrm{DN}$ ), respectively (Fig. 14a). Of the no-data pixels in the darkest and brightest classes of PCA1 DN values, $69.6 \%$ and $38.7 \%$ were on high canopy slopes $\left(>70^{\circ}\right)$, respectively (Fig. 14b)

\section{DISCUSSION}

RMSEs for individual forest blocks in this study varied from 1.01 to $4.19 \mathrm{~m}$ and $78.6 \%$ of the variation could be explained by the SD of canopy height, while the mean error ranged from-1.11 to $1.01 \mathrm{~m}$. Hobi and Ginzler (2012) found that RMSE was as high as $7.06 \mathrm{~m}$ for a forested area in eastern Switzerland, whereas Næsset (2002) reported that mean tree heights were seriously underestimated by -5.2 to $-5.7 \mathrm{~m}$ compared to the true mean tree heights of forest stands assessed using ground measurements as a reference dataset over different forest types characterized by species type (i.e. spruce, pine, mixed). Hese and Lehmann (2000) reported that a photo-DSM was found to perform better in areas of beech species $\left(\mathrm{ME}=1.45 \mathrm{~m} ; R^{2}=0.974\right)$ than in areas of spruce species ( $\left.\mathrm{ME}=3.29 \mathrm{~m} ; R^{2}=0.756\right)$. Photo-DSMs have also been found to be successfully derived from satellite imagery in forest environments, where larger errors would be normally observed mainly due to lower spatial resolution as compared to aerial photographs, as demonstrated by Baltsavias et al. (2008) using IKONOS images (RMSE $=6.61 \mathrm{~m}$ ) and Hobi and Ginzler (2012) using WorldView2 (RMSE=8.02 m) (Table 3).
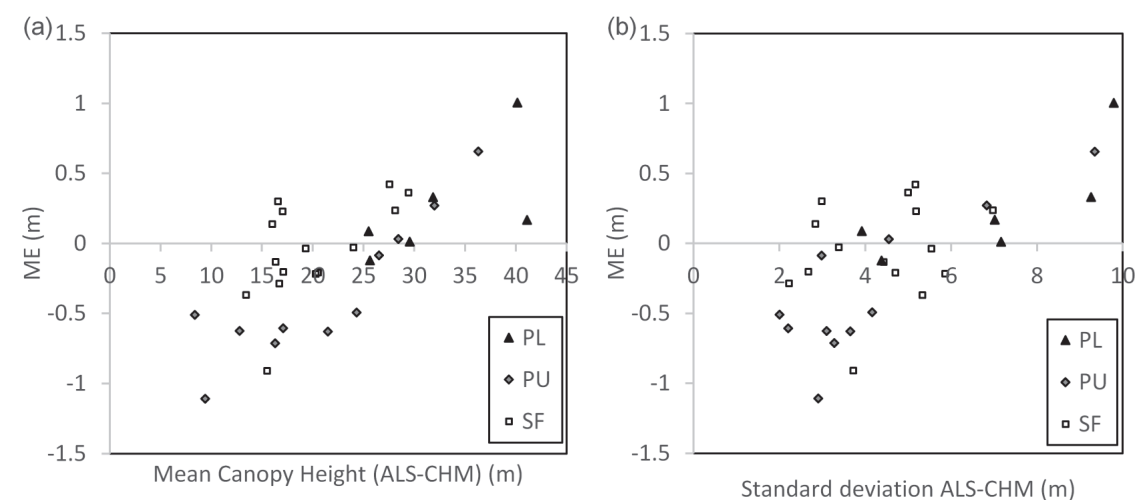

Fig. 9 Mean error (ME) plotted against (a) mean canopy height and (b) SD of the ALSCHM. 


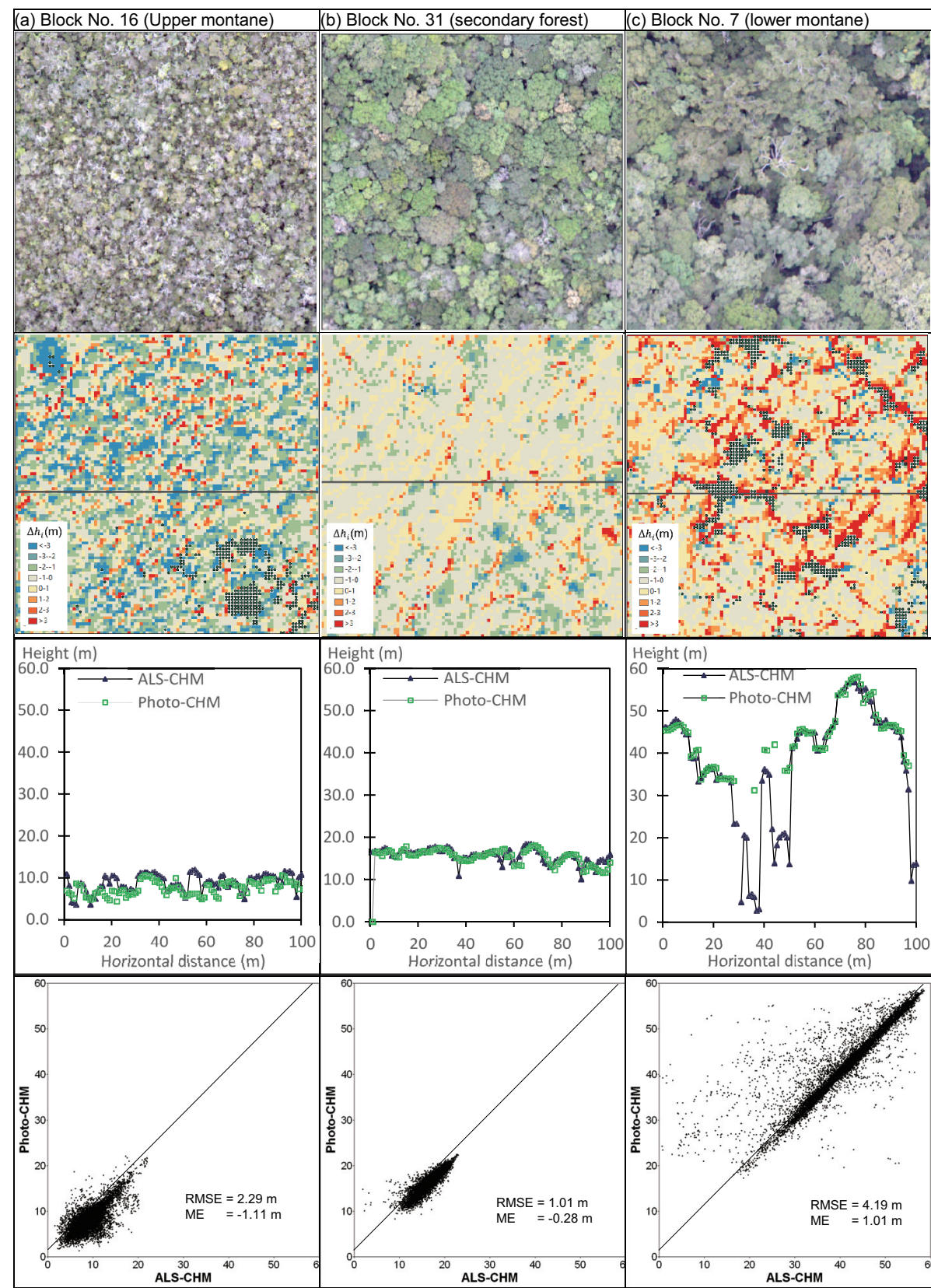

Fig. 10 Color RGB orthophoto (row 1), difference between photo-DSM and ALS-DSM (row 2 ), cross-sectional profile along the line shown in row 2 (row 3), and scatter plot (row 4) in three selected blocks. In the cross-sectional profile, a tree (A) was missed in the upper montane forest while a forest gap (B) was missed in the lower montane forest. Black dots in row 2 are no-data areas.

Our results demonstrated that SD of ALS-CHM, canopy slope, and dark area can all affect the performance of photogrammetric DSMs. Canopy slope was found to influence the RMSE in steeper areas where a small horizontal distance between two points can result in a very high vertical difference. Our RMSE of less than $2 \mathrm{~m}$ for canopy slopes below approximately $50^{\circ}$ was similar to the result reported by Müller et al. (2014). RMSE on the steepest slopes could increase to 4 times (Müller et al., 2014) or 4.5 times (Bühler et al., 2012) that of the RMSE on flat areas. Our RMSE was found to increase by almost 8 times from flattest to the steepest canopy slope. Our study revealed that underestimation tended to occur in gentle canopy slopes, where systematic errors could occur during image-matching process even after co-registration (Müller et al., 2014). The variation of the mean error for the photogrammetric DSM can either be observed when using same software package on different datasets (Müller et al., 2014) or using different software packages on same dataset (Remondino et al., 2014; Sona et al., 2014). For non-forest areas (i.e. bare land and paddy fields), the RMSE did not exceed the value of $0.3928 \mathrm{~m}$ and the accuracies were comparable to those found in several other studies (Table 3), indicating the consistency of the performance of the photogrammetric point cloud. All the RMSEs in those studies (i.e. Hobi and Ginzler, 2012; Müller et al., 2014; Tonkin et al., 2014) did not exceed $1 \mathrm{~m}$ for flat and 

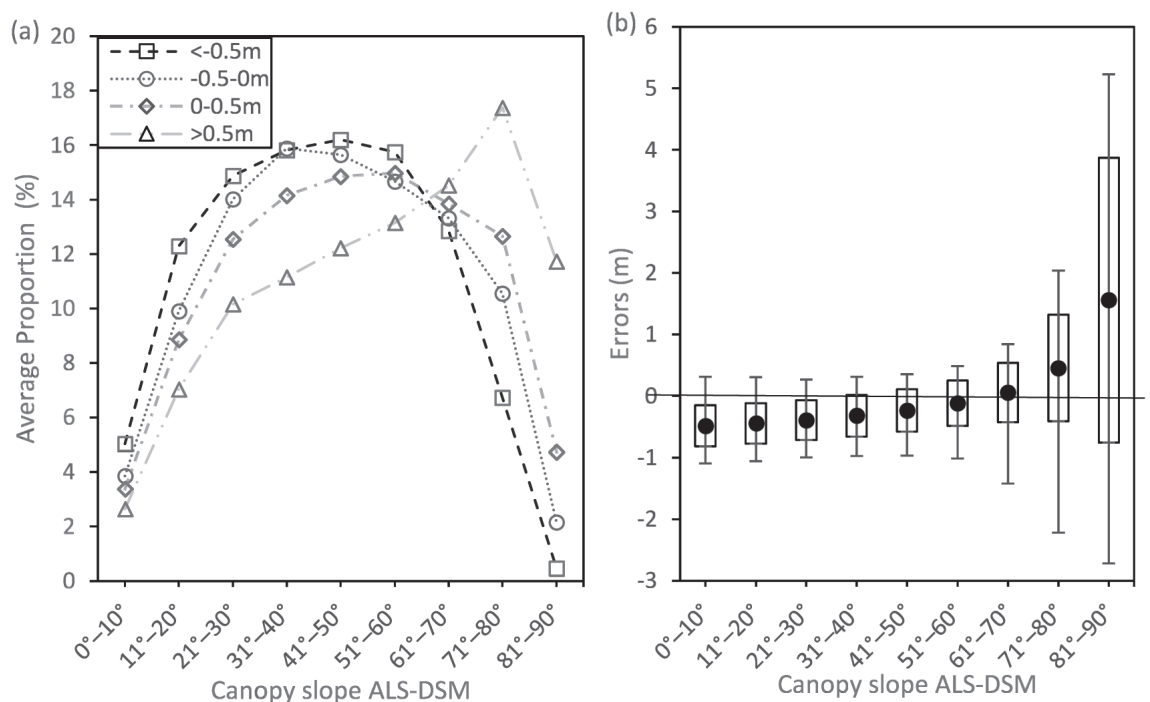

Fig. 11 (a) Average proportion of canopy slope classes (\%) in blocks categorized by four mean error classes (<-0.5 m, $n=7 ;-0.5$ to $0 \mathrm{~m}, n=11$; $>0$ to $0.5 \mathrm{~m}, n=12$; $>0.5 \mathrm{~m}, n=$ 2). (b) Averages of mean error are plotted as circles, boxes are SDs about the mean error, and range of mean error is defined by the line indicating the minimum value at the bottom and the maximum value at top (for each canopy slope class, $n=32$ except for $81^{\circ}-90^{\circ}, n=30$ ).
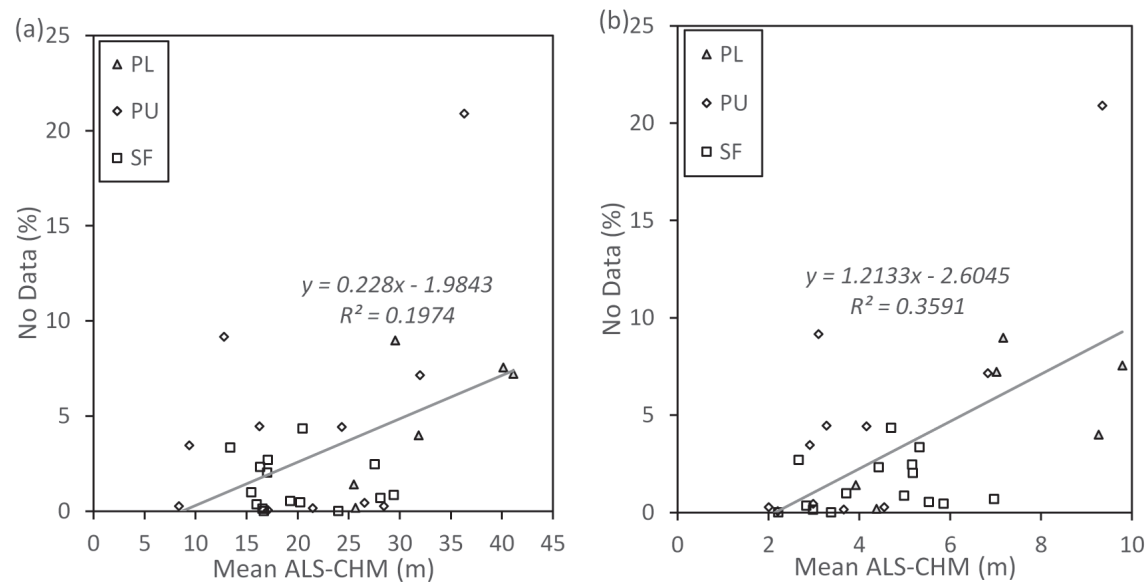

Fig. 12 (a) Percentage of no-data pixels (\%) vs. mean canopy height of the ALS-CHM. (b) No-data pixels (\%) vs. SD of the canopy height of the ALS-CHM $(n=32)$.

non-forest areas when using very high resolution aerial photographs $(\mathrm{GSD}<50 \mathrm{~cm})$.

The major limitation to use of digital photogrammetry for forestry applications can be attributed to the imagematching success, height accuracy including forest gap detection, and that the DEM is only limited to the outer forest canopy. Digital photogrammetry is an indirect technique that derives photogrammetric point-clouds by using the image data taken from passive sensors, unlike the direct height measurements of active sensors (i.e. those emitting and receiving their own energy) such as used with LiDAR and InSAR technology. Therefore, successfully deriving high-accuracy photogrammetric point clouds depends on several factors: (1) image-matching algorithm (Remondino et al., 2014), (2) type of camera/sensor (Müller et al., 2014), (3) camera and flight parameter settings (Agisoft,
2014; Mills et al., 2006), (4) overlap rate (Nurminen et al., 2013), (5) environmental conditions (Nex and Remondino, 2014) and (6) object characteristics (Baltsavias et al., 2008; Remondino et al., 2014; Fabris and Pesci, 2005). A combination of these factors could have influenced the results of image matching in our study site, where $13.9 \%$ of the aerial photographs failed in the camera alignment process. One feasible suggestion to improve the performance is evaluating whether increased forward overlap of up to $90 \%$ (although many recommendations suggest $80 \%$ forward overlap) could improve image-matching success and accuracy in forest environment.

The main advantage of the transition from analytical photogrammetry to digital photogrammetry is the capability to derive height in a dense point-cloud form by a fully automated process unlike in analytical photogrammetry 

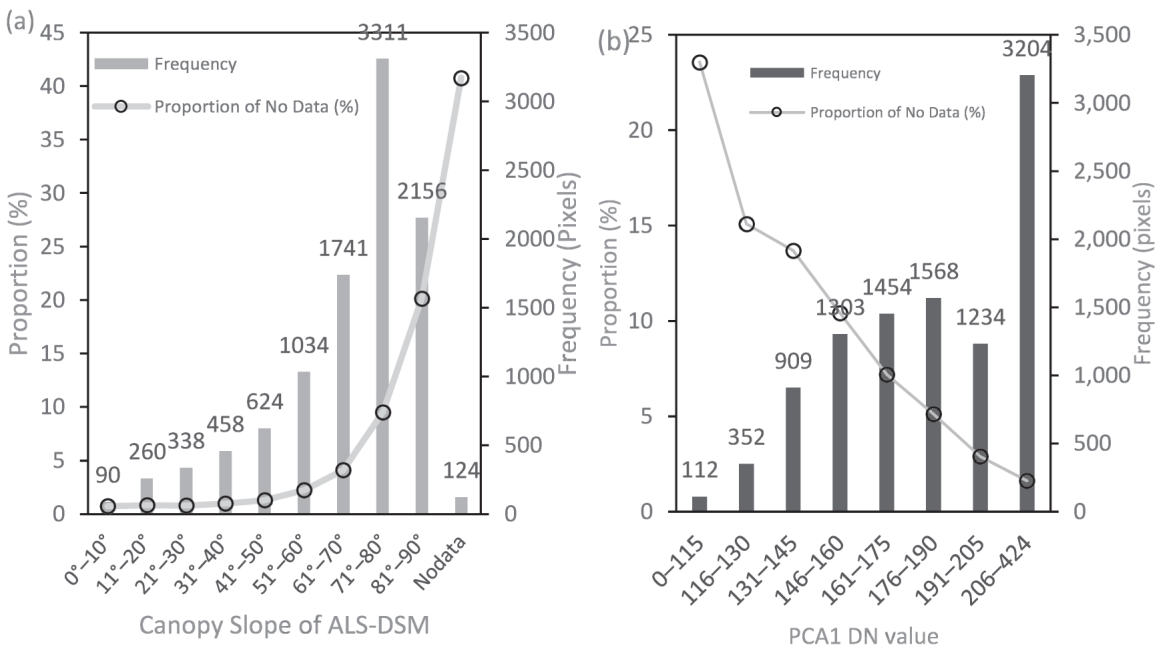

Fig. 13 Proportion (\%) of no-data pixels (left $y$-axis) for the particular class based on (a) ALS-DSM canopy slope class and (b) brightness class (PCA1 DN value). Both right $y$-axes represent the frequency of no-data pixels in each class.
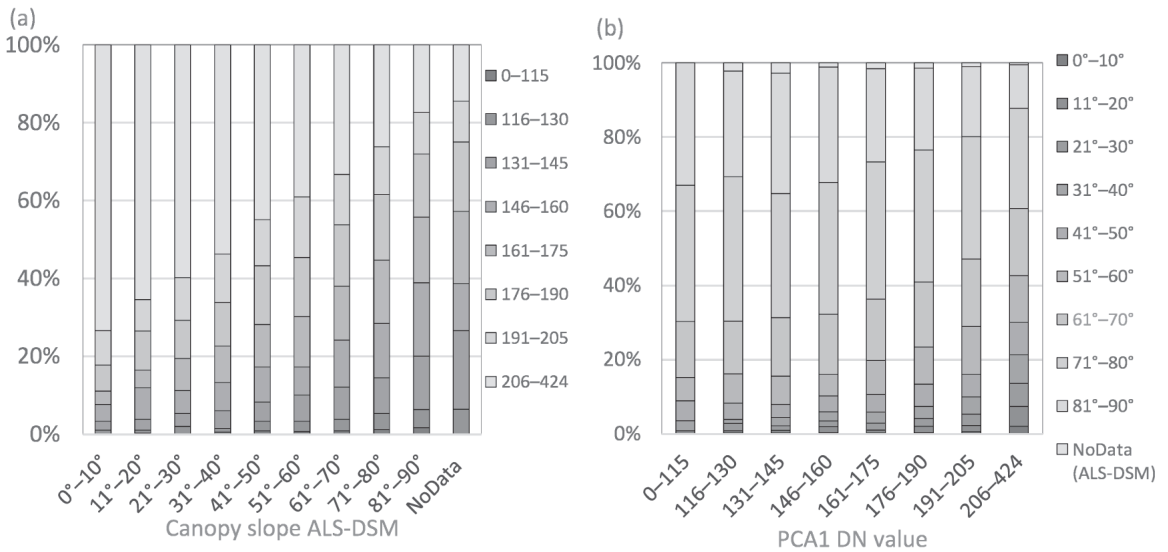

Fig. 14 A 100\% stacked bar chart of cross tabulation for no-data areas between brightness class (PCA1 DN value) and ALS-DSM canopy slope class. (a) Proportion of PCA1 DN value class by different ALS-DSM canopy slope class. (b) Proportion of ALS-DSM canopy slope class by different PCA1 DN value class.

where height must be manually digitized. Our study area (2000 ha) is up to 200 times the size of the study by Fujita et al. (2003a), and by using digital photogrammetry, 935 million points were automatically generated. Additionally, digital photogrammetry is relatively cost-effective in comparison with ALS or InSAR technology. Leberl et al. (2010) reported that the effective strip width for aerial photography is up to 5 times the effective strip width for ALS, and that aircraft can be flown at 2.5 times the speed. This means that aerial photography requires only $8 \%$ of the time that LiDAR needs to cover an area of similar size. However, consideration on accuracy must be taken when flying with higher altitude which will result to a reduced flying times (i.e. lower cost for flight mission) but increased GSD for a given area. Mills et al. (2006) showed that flying height increased the RMSE as the GSD increases, and there is always tradeoff between cost and accuracy. In addition, the advancement of unmanned aerial vehicles allows cameras to be installed and used for smallscale projects, which will significantly reduce costs of such projects (e.g. Lisein et al., 2013; Tonkin et al., 2014).

\section{CONCLUSIONS}

We examined the performance of our photo-DSM in forest area. The RMSE and mean error of our photo-DSM were influenced by metrics of the ALS-CHM (i.e. SD and mean), canopy slope, and dark-area class (derived from PCA of the orthophoto). Standard deviation of the ALS-CHM explained the variance in RMSE by $78.62 \%$. In areas of higher canopy slope, the RMSE increased to $8.63 \mathrm{~m}$, with highest correlation between canopy slope and RMSE occurring at a threshold value of $>70^{\circ}$. The RMSE in dark areas increased to $5.8 \mathrm{~m}$. No-data areas were also influenced by higher ALSDSM canopy slope and dark-area class.

Our findings will be useful when accurate local information is required in forestry applications such as forest dynamics studies, where understanding the degree of overestimation and underestimation is important. However, further research on integrating the photo-DSM with 
Table 3 Performance of photogrammetric DSMs over different forest and non-forest environments

\begin{tabular}{|c|c|c|c|c|}
\hline Study & Sensor (spatial resolution) & Reference dataset & $\begin{array}{l}\text { Forest accuracy/ } \\
\text { type of forest }\end{array}$ & $\begin{array}{l}\text { Non-forest accuracy/ } \\
\text { environment }\end{array}$ \\
\hline \multirow[b]{2}{*}{ Baltsavias et al. (2008) } & \multirow[b]{2}{*}{ IKONOS Pan (1 m) } & \multirow[b]{2}{*}{ ALS } & $6.61 \mathrm{~m}$ (RMSE)/ & $\begin{array}{l}2.05 \mathrm{~m} \text { (RMSE)/ } \\
\text { excluding forest area }\end{array}$ \\
\hline & & & $\begin{array}{l}\text { Deciduous }(80 \%) \text { and } \\
\text { coniferous }(20 \%) \text { forest }\end{array}$ & $1.41 \mathrm{~m}$ (RMSE)/ bare \\
\hline Buhler et al. (2012) & ADS80 $(25 \mathrm{~cm})$ & ALS & $\begin{array}{l}2.55 \mathrm{~m} \text { (RMSE)/ } \\
\text { larch forest }\end{array}$ & $\begin{array}{l}\text { ground } \\
0.82 \mathrm{~m}(\mathrm{RMSE}) / \text { all } \\
0.5 \mathrm{~m} \text { (RMSE) / grassland }\end{array}$ \\
\hline Hese \& Lehmann (2000) & HRSC-A $(30 \mathrm{~cm})$ & $\begin{array}{l}\text { Ground measurement } \\
\text { (Dendrometer) }\end{array}$ & $\begin{array}{l}1.45 \mathrm{~m}(\mathrm{ME}) 0.974\left(R^{2}\right) / \\
\text { beech } \\
3.29 \mathrm{~m}(\mathrm{ME}) 0.756\left(R^{2}\right) / \\
\text { spruce }\end{array}$ & - \\
\hline Hobi \& Ginzler (2012) & $\begin{array}{l}\text { WorldView-2 } \\
\text { (PAN: } 0.5 \mathrm{~m} / \mathrm{MS}: 1.84 \mathrm{~m}) \\
\text { ADS80 }(25 \mathrm{~cm})\end{array}$ & ALS & $\begin{array}{l}7.06 \text { m (RMSE) for ADS80 } \\
8.02 \text { m(RMSE) for WV2/ } \\
\text { eastern Swiss plateau }\end{array}$ & $\begin{array}{l}0.85 \mathrm{~m} \text { (RMSE) / grass and } \\
\text { herb vegetation }\end{array}$ \\
\hline Mills et al. (2006) & $\operatorname{ADS} 40(15,20,25,30 \mathrm{~cm})$ & ALS & 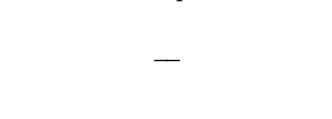 & $\begin{array}{l}0.58 \text { (RMS) / flat } \\
0.60 \text { (RMS)/ hilly } \\
1.66(\mathrm{RMS}) / \text { urban }\end{array}$ \\
\hline Müller et al. (2014) & $\begin{array}{l}\text { HRSC-A }(\sim 10 \mathrm{~cm}) \\
\operatorname{RC} 30(\sim 40 \mathrm{~cm}) \\
\text { ADS40 }(\sim 50 \mathrm{~cm}) \\
\text { ADS80 }(\sim 50 \mathrm{~cm})\end{array}$ & ALS \& Geodetic survey & - & $\begin{array}{l}1 \text { to } 1.3 \mathrm{~m} \text { (RMSE)/ } \\
\text { mountain environment }\end{array}$ \\
\hline Næsset (2002) & $\begin{array}{l}\text { Agfa Aviphot Pan } 200 \text { PE1 } \\
(19 \mathrm{~cm})\end{array}$ & Ground measurement & $\begin{array}{l}-5.42 \mathrm{~m}(\mathrm{ME}) / \text { all } \\
-5.68 \mathrm{~m}(\mathrm{ME}) / \text { spruce, } \\
-5.20 \mathrm{~m}(\mathrm{ME}) / \text { pine } \\
-5.31 \mathrm{~m}(\mathrm{ME}) / \text { mixed forest }\end{array}$ & - \\
\hline Tonkin et al. (2014) & $\begin{array}{l}\text { Canon EOS-M } 18 \mathrm{MP} \text { in Uas } \\
(<3 \mathrm{~cm})\end{array}$ & Geodetic (Total station) & - & $\begin{array}{l}0.517 \mathrm{~m} \text { (RMSE)/ } \\
\text { moraine-mound complex }\end{array}$ \\
\hline
\end{tabular}

Note: Agfa Aviphot Pan 200 PE1 and RC30 are analogue camera system; HRSC-A, ADS40 and ADS80 are multi-sensor pushbroom instrument; Canon EOS-M is a small-format consumer digital camera; WorldView-2 and IKONOS are satellite sensors.

delineation of individual tree crowns will be needed to assess the accuracy at the single-tree level. The $86.1 \%$ success rate of fully automatic image matching achieved in our study offers great potential for conducting operational tasks at relatively low cost in large forest areas, such as in estimating changes in forest canopy height over past decades or monitoring forest carbon under REDD+ (reducing emissions from deforestation and forest degradation).

To further develop photogrammetric DEMs for forestry applications and to increase the robustness of this technology, continuous research is needed over several broad topics including study of flight parameters for achieving costeffective and optimum accuracy, gap detection and height correction, DTM correction, improvement in estimations of forest variables, as well as continuous evaluation in different forest types.

\section{ACKNOWLEDGEMENTS}

This research project was supported by the Advanced Carbon Monitoring in Asian Tropical Forest by High Precision Remote Sensing Technology project of the Ministry of Agriculture, Fishery and Forestry (MAFF), Japan.

\section{LITERATURE CITED}

Agisoft (2014) Agisoft PhotoScan User Manual: Professional Edition, Version 1.1. http://www.agisoft.com/pdf/ photoscan_1_1_en.pdf (Accessed on Sep. 1, 2015)

Awaya, Y., Tanaka, N., Tanaka, K., Takao, G., Kodani, E. and Tsuyuki, S. (2000) Stand parameter estimation of artificial evergreen conifer forests using airborne images: An evaluation of seasonal difference on accuracy and best wavelength. J. For. Res. 5: 247-258

Baltsavias, E., Gruen, A., Eisenbeiss, H., Zhang, L. and Waser, L.T. (2008) High-quality image matching and automated generation of 3D tree models. Int. J. Remote Sens. 29: 12431259

Barker, M.G. and Pinard, M.A. (2001) Forest canopy research: sampling problems, and some solutions. Plant Ecol. 153: 2338

Bohlin, J., Wallerman, J. and Fransson, J.E.S. (2012) Forest variable estimation using photogrammetric matching of digital aerial images in combination with a high-resolution DEM. Scand. J. For. Res. 27: 692-699

Bongers, F. (2001) Methods to assess tropical rain forest canopy structure: an overview. Plant Ecol. 153: 263-277

Brown, S., Pearson, T., Slaymaker, D., Ambagis, S., Moore, N., Novelo, D. and Sabido, W. (2005) Creating a virtual tropical 
forest from three-dimensional aerial imagery to estimate carbon stocks. Ecol. Appl. 15: 1083-1095

Bühler, Y., Marty, M. and Ginzler, C. (2012) High resolution DEM generation in high-alpine terrain using airborne remote sensing techniques. Trans. GIS 16: $635-647$

Carswell, F.E., Meir, P., Wandelli, E. V., Bonates, L.C.M., Kruijt, B., Barbosa, E.M., Nobre, a. D., Grace, J. and Jarvis, P.G. (2000) Photosynthetic capacity in a central Amazonian rain forest. Tree Physiol. 20: 179-186

Erwin, T.L. (1983) Tropical forest canopies: The last biotic frontier. Bull. ESA 29: 14-20

Fabris, M. and Pesci A. (2005) Automated DEM extraction in digital aerial photogrammetry: precisions and validation for mass movement monitoring. Ann. Geophysics 48: 973988

Fujita, T., Itaya, A., Miura, M., Manabe, T. and Yamamoto, S. (2003a) Canopy structure in a temperate old-growth evergreen forest analyzed by using aerial photographs. Plant Ecol. 168: 23-29

Fujita, T., Itaya, A., Miura, M., Manabe, T. and Yamamoto, S.-I. (2003b) Long-term canopy dynamics analysed by aerial photographs in a temperate old-growth evergreen broadleaved forest. J. Ecol. 91: 686-693

Garzon-Lopez, C.X., Bohlman, S. a., Olff, H. and Jansen, P. A. (2013) Mapping tropical forest trees using high-resolution aerial digital photographs. Biotropica 45: 308-316

Gobakken, T., Bollandsås, O.M. and Næsset, E. (2015) Comparing biophysical forest characteristics estimated from photogrammetric matching of aerial images and airborne laser scanning data. Scand. J. For. Res. 30: 73-86

Grubb, P.J. (1971) Interpretation of the "Massenerhebung" effect on tropical mountains. Nature 229: 44-45

Hawbaker, T.J., Keuler, N.S., Lesak, A.A., Gobakken, T., Contrucci, K. and Radeloff, V.C. (2009) Improved estimates of forest vegetation structure and biomass with a LiDARoptimized sampling design. J. Geophys. Res. 114: 1-11

Hese, S. and Lehmann, F. (2000) Comparison of Digital Stand Surface Models Of HRSC-A (High Resolution Stereo Camera - Airborne) and Laser Scanner for Forest Stand. In: International Archives of Photogrammetry and Remote Sensing 33: 525-532.

Hirata, Y., Tabuchi, R., Patanaponpaiboon, P., Poungparn, S., Yoneda, R. and Fujioka, Y. (2014) Estimation of aboveground biomass in mangrove forests using highresolution satellite data. J. For. Res. 19: 34-41

Hobi, M.L. and Ginzler, C. (2012) Accuracy assessment of digital surface models based on WorldView-2 and ADS80 stereo remote sensing data. Sensors (Switzerland) 12: 63476368.

Hyyppa, J., Pyysalo, U., Hyyppa, H., Haggren, H. and Ruppert, G. (2000) Accuracy of laser scanning for DTM generation in forested areas. In: Proceedings of SPIE - The International Society for Optical Engineering 4035: 119-130

Imai, N., Samejima, H., Langner, A., Ong, R.C., Kita, S., Titin, J., Chung, A.Y.C., Lagan, P., Lee, Y.F. and Kitayama, K. (2009) Co-benefits of sustainable forest management in biodiversity conservation and carbon sequestration. PLoS ONE 4: e8267

Ioki, K., Tsuyuki, S., Hirata, Y., Phua, M.-H., Wong, W.V.C.,
Ling, Z.-Y., Saito, H. and Takao, G. (2014) Estimating aboveground biomass of tropical rainforest of different degradation levels in Northern Borneo using airborne LiDAR. For. Ecol. Manage. 328: 335-341

Järnstedt, J., Pekkarinen, A., Tuominen, S., Ginzler, C., Holopainen, M. and Viitala, R. (2012) Forest variable estimation using a high-resolution digital surface model. ISPRS J. Photogramm. Remote Sens. 74: 78-84

Kardoš,M. (2013) Methods of digital photogrammetry in forest management in Slovakia. J. For. Sci. 59: 54-63

Kays, R. and Allison, A. (2001) Arboreal tropical forest vertebrates: current knowledge and research trends. Plant Ecol. 153: 109-120

Khosravipour, A., Skidmore, A.K., Wang, T., Isenburg, M. and Khoshelham, K. (2015) Effect of slope on treetop detection using a LiDAR Canopy Height Model. ISPRS J. Photogramm. Remote Sens. 104: 44-52

Kitayama, K. (1992) An altitudinal transect study of the vegetation on Mount Kinabalu, Borneo. Vegetatio 102: 149171

Leberl, F., Irschara, A., Pock, T., Meixner, P., Gruber, M., Scholz, S. and Wiechert, A. (2010) Point clouds: Lidar versus 3D vision. Photogramm. Eng. Remote Sensing. 76: 11231134

Lisein, J., Pierrot-Deseilligny, M., Bonnet, S. and Lejeune, P. (2013) A photogrammetric workflow for the creation of a forest canopy height model from small unmanned aerial system imagery. Forests 4: 922-944

Lowman, M.D. and Wittman, P.K. (1996) Forest canopies: Methods, hypotheses, and future directions. Annu. Rev. Ecol. Syst. 27: 55-81

Miller, D.R., Quine, C.P. and Hadley, W. (2000) An investigation of the potential of digital photogrammetry to provide measurements of forest characteristics and abiotic damage. For. Ecol. Manage. 135: 279-288

Mills, J.P., Alhamlan, S., Abuoliat, A.S. and Horgan, J. (2006) Geometric validation of imagery and products from a high performance airborne digital sensor. Int. Arch. Photogrammetry Remote Sens. Spatial Inf. Sci. 36: 301-305.

Morgan, J.L., Gergel, S.E. and Coops, N.C. (2010) Aerial photography: A rapidly evolving tool for ecological management. BioScience 60: 47-59

Müller, J., Gärtner-Roer, I., Thee, P. and Ginzler, C. (2014) Accuracy assessment of airborne photogrammetrically derived high-resolution digital elevation models in a high mountain environment. ISPRS J. Photogramm. Remote Sens. 98: 58-69

Nadkarni, N.M. (1994) Diversity of species and interactions in the upper tree canopy of forest ecosystems. Am. Zool. 34: 70-78

Næsset, E. (2002) Determination of mean tree height of forest stands by digital photogrammetry. Scand. J. For. Res. 17: $446-459$

Nakashizuka, T., Katsuki, T. and Tanaka, H. (1995) Forest canopy structure analyzed by using aerial photographs. Ecol. Res. 10: 13-18

Nex, F. and Remondino, F. (2014) UAV for 3D mapping applications: a review. Appl. Geomatics 6: 1-15

Nurminen, K., Karjalainen, M., Yu, X., Hyyppä, J. and 
Honkavaara, E. (2013) Performance of dense digital surface models based on image matching in the estimation of plotlevel forest variables. ISPRS J. Photogramm. Remote Sens. 83: $104-115$

Okuda, T., Suzuki, M., Numata, S., Yoshida, K., Nishimura, S., Adachi, N., Niiyama, K., Manokaran, N. and Hashim, M. (2004) Estimation of aboveground biomass in logged and primary lowland rainforests using 3-D photogrammetric analysis. For. Ecol. Manage. 203: 63-75

Parker, G.G. and Brown, M.J. (2000) Forest canopy stratification-Is it useful? Am. Nat. 155: 473-484

Parker, G.G., Smith, A.P. and Hogan, K.P. (1992) Access to the upper forest canopy with a large tower crane. BioScience. 42: $664-670$

Pascual, C., García-Abril, A., Cohen, W.B. and MartínFernández, S. (2010) Relationship between LiDAR-derived forest canopy height and Landsat images. Int. J. Remote Sens. 31: 1261-1280

Pearce, K.G. (2006) The flora of Pulong Tau National Park. ITTO, Yokohama, 201pp

Phua, M.-H., Tsuyuki, S., Furuya, N. and Lee, J.S. (2008) Detecting deforestation with a spectral change detection approach using multitemporal Landsat data: a case study of Kinabalu Park, Sabah, Malaysia. J. Environ. Manage. 88: 784-795

Rahlf, J., Breidenbach, J., Solberg, S., Næsset, E. and Astrup, R. (2014) Comparison of four types of 3D data for timber volume estimation. Remote Sens. Environ. 155: 325-333

Remondino, F., Spera, M.G., Nocerino, E., Menna, F. and Nex, F. (2014) State of the art in high density image matching. Photogramm. Rec. 29: 144-166

Sabah Biodiversity Conservation Project (SBCP) (1998) Identification of potential protected areas: Ulu Padas final report. Ministry of Culture, Environment and Tourism Malaysia. http://ww2. sabah.gov.my/jpas/programs/ biodiversity/ulupadas.pdf (Accessed on Sep. 1, 2015)

Snavely, N., Seitz, S. and Szeliski, R. (2008) Modeling the world from internet photo collections. Int. J. Comput. Vis. 80: 189210

Soininen, A., 2010. TerraScan User's Guide. TerraSolid Ltd

Sona, G., Pinto, L., Pagliari, D., Passoni, D. and Gini, R. (2014)

Experimental analysis of different software packages for orientation and digital surface modelling from UAV images. Earth Sci. Inform. 7: 97-107

Straub, C., Stepper, C., Seitz, R. and Waser, L.T. (2013) Potential of UltraCamX stereo images for estimating timber volume and basal area at the plot level in mixed European forests. Can. J. For. Res. 43: 731-741

Tonkin, T.N., Midgley, N.G., Graham, D.J. and Labadz, J.C. (2014) The potential of small unmanned aircraft systems and structure-from-motion for topographic surveys: A test of emerging integrated approaches at Cwm Idwal, North Wales. Geomorphology 226: 35-43

Valérie, T. and Marie-Pierre, J. (2006) Tree species identification on large-scale aerial photographs in a tropical rain forest, French Guiana-application for management and conservation. For. Ecol. Manage. 225: 51-61

Vastaranta, M., Wulder, M.A., White, J.C., Pekkarinen, A., Tuominen, S., Ginzler, C., Kankare, V., Holopainen, M., Hyyppä, J. and Hyyppä, H. (2013) Airborne laser scanning and digital stereo imagery measures of forest structure: comparative results and implications to forest mapping and inventory update. Can. J. Remote Sens. 39: 382-395

Vermeulen, C., Lejeune, P., Lisein, J., Sawadogo, P. and Bouché, P. (2013) Unmanned aerial survey of elephants. PLoS ONE 8: e54700

White, J., Wulder, M., Vastaranta, M., Coops, N., Pitt, D. and Woods, M. (2013) The Utility of Image-Based Point Clouds for Forest Inventory: A Comparison with Airborne Laser Scanning. Forests 4: 518-536

Wong, W., Tsuyuki, S., Nakakita, O., Furuya, N., Ioki, K. and Phua, M.H. (2014) Assessment of forest canopy structure using digital aerial photogrammetry in tropical forest, Northern Borneo. In: $125^{\text {th }}$ Annual Japanese Forest Society Meeting. https://www.jstage.jst.go.jp/article/jfsc/125/0/ 125_79/_article (Accessed on Sep. 1, 2015)

Wong, W., Tsuyuki, S., Ioki, K., Phua, M.H. and Takao, G. (2015) Forest biophysical characteristics estimation using digital aerial photogrammetry and airborne laser scanning for tropical montane forest. In: $36^{\text {th }}$ Asian Conference on Remote Sensing 2015. 10pp

(Received 2 October 2015)

(Accepted 1 December 2015) 